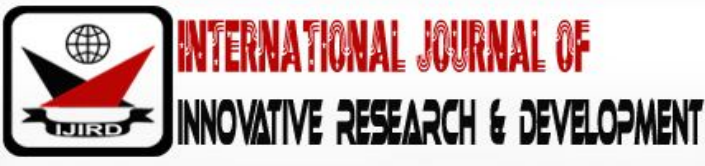

ISSN 2278 - 0211 (Online)

\section{The Broadloom as a Machine for the Production of Innovative Upholstery Fabric Design}

Edward Apau
Lecturer, Sunyani Technical University, Sunyani, Ghana
A.F. Ibrahim
Senior Lecturer, Takoradi Technical University, Takoradi, Ghana
Genevieve Huedenu
Lecturer, Department of Pre-Vocational Skills, Holy Child Teacher Training College, Takoradi, Ghana

\begin{abstract}
:
Weaving is identified as one of the ancient forms of fabric construction. It gives meaning and identity about the people as far as their beliefs, religion and traditions are concerned. Upholstery fabric designs for furniture employed in Ghana are imported and are of foreign influence. Even though these fabrics have their aesthetic and functional values, observations proved that upholstery fabric designs can be hand-woven to give meaning and identity to furniture. In view of this, the study identifies and selects suitable weave structures that can be hand-woven to satisfy furniture decoration. The study reveals the possibilities of using the broadloom to weave upholstery fabric designs. Types of Upholstery fabrics and their characteristics were reviewed based on the conceptual and theoretical framework of the study. Descriptive and studio/practice-based research methods were employed under qualitative research approach as the research design for the study. The study further presents systematic processes involved in producing design samples. The study unearths the aesthetical and functional purposes of hand weaving in upholstery fabric designs. Even though, there were merits and demerits of the woven samples, the durability of hand-woven and machine-woven fabrics for upholstery depends on the type of yarns, weave structures and most importantly the rate and exposure of the furniture. It is therefore recommended that, the skills of hand-weaving should be encouraged and further studio practice should be carried out to increase the knowledge of hand-woven fabrics in other textile applications.
\end{abstract}

Keywords: Broadloom machine, production, innovation, upholstery, fabric design

\section{Introduction}

The relationship between design and production is the planning and execution of a conceived idea or plan. The plan should anticipate and compensate for potential problems in the execution process. Design involves problem-solving and creativity. In contrast, production involves a routine or pre-planned process. A design may also be a mere plan that does not include a production or engineering process, although a working knowledge of such processes is usually expected of designers (Ward, 2010). According to Seymour (2002), a design does not have to be new, different or impressive to be successful in the market place, but it must fulfill a need. He however, explained that, the processes of designing do lead to innovative products and services. Textiles span many categories of human want and need. Modern manufacturers distinguish apparel textiles for the body from the coverings of walls and furniture. Hand-made cloth supplies equally varied domains. Within each domain, some fabrics meet practical demands while others communicate meanings or express artistic taste (Schneider, 1987). Textile design associates itself to the making of creative, stylish and contemporary designs. It requires special skills to create innovative designs. The core areas of textile designing involves the following: designing fabric by using different techniques comprising printing, weaving, ornamenting fabric, print technique, tracing embroidery and colour detailing, providing support to the clients to visualize the design and helping the clients correct samples while executing prototypes (Textile Design, 2010). "Upholstery" according to the Columbia Encyclopaedia (2010) is a general term used to describe household fittings, hangings, curtains, cushions and covers. It also refers to stuffed, padded and spring-cushioned furniture, such as chairs and sofas, or to the usually decorative materials and fabrics that cover them. Maxin (2010) explains that, in textile upholstery, fabrics, plastics, leather and synthetic leather serve as furniture coverings. The appearance of upholstery fabrics is the most visible indication of fashion and quality, and nothing has a great effect on the look of upholstered furniture than the fabric designs. Moreover, upholstery fabrics need to be attractive and also make the furniture comfortable and durable. 
A pre-study conducted by the researchers proved that, plastic, synthetic leather, leather and machine-woven fabric designs have flooded furniture upholstery in Ghanaian homes and offices. These woven fabrics are produced with designs under foreign influence which lack the creativity and meaning of Ghanaian identity. Some of these fabric designs from the researcher's point of view can be created with hand-woven skills locally to serve the same purpose of furniture decoration. Albers (1974) adds that, with only a few exceptions all fabric constructions are elaborations or combinations of the basic weaves. With reference to Albers' statement, the researcher is of the view that, some upholstery fabric designs can be handwoven locally with the broadloom to suit furniture decoration. In spite of the fact that the broadloom has a limitation of four shafts, there are possibilities of exploring different weave structures within the construction of a particular fabric design. Again, there are certain unique weave and colour effects that can be achieved in hand-woven fabrics which can influence the aesthetic and visual appeal of furniture. In view of this, the project seeks to design and produce weave structures using the broadloom with the aim of discovering innovative upholstery fabric designs and to encourage the use of locally made upholstery fabrics. Albers (1974) adds that, with only a few exceptions all fabric constructions are elaborations or combinations of the basic weaves. With reference to Albers' statement, the researcher is of the view that, some upholstery fabric designs can be hand-woven locally with the broadloom to suit furniture decoration. In spite of the fact that the broadloom has a limitation of four shafts, there are possibilities of exploring different weave structures within the construction of a particular fabric design. Again, there are certain unique weave and colour effects that can be achieved in hand-woven fabrics which can influence the aesthetic and visual appeal of furniture. In view of this, the project seeks to design and produce weave structures using the broadloom with the aim of discovering innovative upholstery fabric designs and to encourage the use of locally made upholstery fabrics. The word "Design" is employed in almost all disciplines of art. Its use can have a perspective meaning depending on the conceptual application of the word. A design can be defined as a "plan within a work of art" but this definition is seemingly basic to the art world including textiles. However, the term is reviewed from other authors to understand its conceptual applications. According to Seymour (2002) design could be viewed as an activity that translates an idea into blue print for something useful, whether it is graphical, textiles, ceramics, service or process. The most important part of designing is translation of idea. A design doesn't have to be new, different or impressive to be successful in the market field, as long as it is fulfilling a need, but design methods do lead to innovative products and services. Broadly stated, design is the art of creation. More technically speaking, design is the conscious, deliberate process by which elements, components, potentials, and tendencies just to mention a few are intentionally arranged in the space-time continuum in order to achieve a desired result. In its fullest, most potent expression, design is the imagining and bringing forth of new worlds or ideas (Mare, 2009). Miller (2009) explains that, design is also intuition, that form of subconscious thought that leads to a deeper sense of knowing, often in the apparent absence of rational confirmation. Intuition is akin to an elongated insight that tells us we are on to something. It is the hunch that often underlies our efforts to perform rational analysis. It also involves reason, that fully conscious form of thought that assesses the problem and analyzes the possibilities for solution. It is the analytical process that relies on method and mathematics to assess, refine, and verify its various hypotheses. Design, on the other hand, can be a conscious effort to create something that is both functional and aesthetically pleasing. For example, a graphic artist may design an advertisement poster. This person's job is to communicate the advertisement message (functional aspect) and to make it look good (aesthetically pleasing). It further explains that, design is often viewed as a more rigorous form of art, or art with a clearly defined purpose (Design and Art, 2009).

Dziers (2006) is of the view that, textile design associates itself in making creative, stylish and contemporary designs. Textile design requires special skills to create innovative designs. He added that, the core of textile designing is concept of designing fabric by using different techniques comprising printing, weaving, ornamenting fabric, print technique, tracing embroidery and colour detailing. It also provides support to clients to visualize the design and to assist them to correct samples while executing prototypes. Textile design is not the same as textile production, although textile designers would benefit from working with various fabrics and materials. Textile designers create designs on textiles and they use fabrics, cloth, and upholstery to fashion a wide range of products. Textiles are the basis of linens, bathing products, fashion, interior design, and furniture. And, textiles have grown up to branch out into installation art.

Furthermore, Textile designers plan and develop patterns, knit and weave construction, prints, textures and illustrations for fabrics and other materials that require the development of patterned surfaces. They plan the way a fabric looks and performs. They design the structure of the fabric and make decisions about appropriate yarns, colour use, surface patterning, texture and finishing (What is Textile Design, 2010). Textile designers develop fabrics used in furniture, soft furnishings, clothing, vehicles and products such as luggage. They can apply the same skills to the development of patterns for wallpapers, laminates and patterned plastics. They design fabrics to satisfy marketing and manufacturing requirements. They balance aesthetic and functional aspects; they consider the nature of yarn types, thicknesses, weights and textures to produce fabrics to cost and production constraints. This source concludes that, textile designers advise and liaise with others who work in industries where it is necessary to predict future colour trends. They monitor trends in industries such as interior design, automotive design and fashion and progressively evolve fabric styles to meet these specific needs (Textile Design, 2009).

The review of "design" exposes and explains the conceptual application of the word in various fields of study. From (Design and Art, 2009) a created design should serve both functional and aesthetical purposes. Furthermore, the researchers agree with Dziers (2006), who states that, Textile designing is the creation of stylish and contemporary designs. Again, it requires special skills to create innovative designs. The researchers are of the view that, the understanding derived from these 
authorities will assist in the creating challenging fabric designs which will serve both aesthetical and functional purposes for upholstery fabrics.

In textiles, fabrics are manufactured in wide varieties and designs. And different designs and effects are produced on fabric with various mechanisms which are helpful to form different weaves and lots of design which enhances the look of apparels. Weaving is the one of the various mechanisms of fabric manufacturing and another conceptual term of the study that needs to be discussed.

Tortora and Merkel (2005) define weaving as the method or process of interlacing two or more sets of yarns or similar materials so that they cross each other at usually right angles to produce woven fabric. It further explains it is the act of causing two systems of yarn, warp and filling, to interlace. This may be done on a power or hand loom or by several manual methods. Weaving is the textile art in which two distinct sets of yarns or threads, called the warp and the filling or weft (older woof), are interlaced with each other to form a fabric or cloth. The warp threads run lengthways of the piece of cloth, and the weft runs across from side to side. Cloth is woven on a loom, a device for holding the warp threads in place while the filling threads are woven through them. Weft is an old English word meaning "that which is woven".

It concludes that, weaving in general involves the interlacing of two sets of threads at right angles to each other: the warp and the weft (Weaving, 2010). The basic concept of fabric weaving explains the use of two sets of yarns namely warp yarns and weft yarns. The warp yarns are aligned parallel and run lengthwise in the fabric with tension for easy shedding. However, the weft yarns are used to interlace the warp crosswise at right angle in a certain order which defines the character of the fabric. In reference of the sets of yarns, tenacity should be Kelley (2009) states that, the term "Upholstery" refers to sofas, chairs and other seating with permanently attached covers of a fabric or leather. She explains that, two important features of Upholstery fabrics are form and function.

"Upholstery" according to (Columbia Encyclopaedia, 2009) is a general term for household fittings, hangings, curtains, cushions and covers. It also refers to stuffed, padded and spring-cushioned furniture, such as chairs and sofas, or to the usually decorative materials and fabrics that cover them. Upholstery is the work of providing furniture, especially seats, with padding, springs, webbing, and fabric or leather covers. The word upholstery comes from the Middle English words - Up and Holden, meaning "to hold up". The term is applied to domestic furniture and also to automobiles, airplanes and boats (Upholstery, 2010).

The conceptual application of "Upholstery" in the project is defined as the decorative materials and fabrics used in covering furniture, specifically woven Upholstery fabrics.

Kelley (2009) states that, the term "Upholstery" refers to sofas, chairs and other seating with permanently attached covers of a fabric or leather. She explains that, two important features of Upholstery fabrics are form and function "Upholstery" according to (Columbia Encyclopaedia, 2009) is a general term for household fittings, hangings, curtains, cushions and covers. It also refers to stuffed, padded and spring-cushioned furniture, such as chairs and sofas, or to the usually decorative materials and fabrics that cover them. Upholstery is the work of providing furniture, especially seats, with padding, springs, webbing, and fabric or leather covers. The word upholstery comes from the Middle English words - Up and Holden, meaning "to hold up". The term is applied to domestic furniture and also to automobiles, airplanes and boats (Upholstery, 2010). The conceptual application of "Upholstery" in this project is defined as the decorative materials and fabrics used in covering furniture, specifically woven Upholstery fabrics. Woven fabrics are produced as result of interlacing two sets of yarns, warp and weft which runs lengthwise and crosswise respectively in the fabric. The order of successive movements between these two sets of yarns determines the physical appearance of the fabric identified as the weave or the structure. Furthermore, fabric weaves are regarded as the structural pattern of different fabrics. Without the fabric weave, fabric may never be constructed. How loose, decorative, tight, nubby or soft a certain fabric is, depends largely on the fabric weave. They can also cause a huge variance regarding the fabrics durability or strength.

Luther (2010) states that, there are many kinds of fabric weave. The most common ones are Twill; Rib, Plain, Oxford, Basket, Satin, Uncut Pile, Chenille Weave, Dobby, Cut Pile, Double Knit, Leno, and Jacquard. Furthermore, fabric weaves are different methods wherein the various types of fabric are manufactured. There are actually a lot of different fabric weaves that are initially made due to various purposes. Also, they can help in determining exactly how durable particular clothing is. Figuring out which type of weave works best for a specific type of clothing can prevent having an end product that easily becomes frayed.

Wynne (1997) states that, a weave refers to the order of interlacing of the warp ends or the weft picks. She further explains that, a weave repeat is the smallest number of threads required to show all of the interlacing in the pattern. She adds that, weaves fall into three main categories, namely Basic weaves (which are the most popular and include plain, twill, satin and those weaves that are developed from them), Fancy weaves and Compound weaves.

Grosicki (1975) again explains that, woven structures may be conveniently divided into two principal categories, as follows; Simple structures in which the ends and the picks intersect one another at right angles and in the cloth are respectively parallel to each other, and Compound weaves which there may be more than one series of ends or picks some of which may be responsible for the "body" of the fabric such as the ground yarns, whilst some may be employed entirely for ornamental purposes such as "figuring" or "face" yarns. Woven cloth can be plain (in one colour or a simple pattern), or it can be woven in decorative or artistic designs, including tapestries. Fabric in which the warp and/ or weft is tie-dyed before weaving is called ikat. There are a variety of weaving techniques used to make fabrics. The techniques range from the simple, such as plain weave to elaborate, such as tapestry. The weight and quality of a woven fabric depends on the weaving 
techniques used to produce it. Perhaps the simplest of all weaving techniques is the plain weave, which is generally used to produce lightweight, almost sheer fabrics such as muslin and cotton lawn (Parma, 2010).

Jacquard weaves, produced on a special loom, are characterized by complex woven-in designs, often with large design repeats or tapestry effects. Dobby weaves, requiring a special loom attachment, have small, geometric, textured, frequently repeated woven-in designs, as seen in bird's-eye piqué. Leno weaves, also made with a special attachment, are usually lightweight and open, giving a lace-like appearance, and are made by twisting adjacent warp yarns around each other, then passing the filling yarn through the twisted warps. Marquisette, casement cloth, and mosquito netting are produced by this method (Chandler, 2011). The types of weaves have often been mistaken for types of fabrics. Each different fibre content advances towards the hand and drape of the fabric. There are many different types of weaves. Some are plain and some are fancy, but all use the basic "under \& over" technique of weaving. The basic types of weaves are Plain weave, Twill weave and Satin weave (Types of weaves, 2007). Pile weaves have cut or uncut loops that stand up on the surface of the fabric. Velvet and chenille are pile weaves. Jacquard weaves have a woven-in design created on a special loom. Damasks, tapestries and brocades are all Jacquard weaves. Novelty weaves however, are created by using a variation or a combination of the basic weaves (Upholstery basics, 2009). Mabey (2010) identifies plain, decorative and pile as some of the many categories of weaves commonly used to make upholstery fabrics. The plain weave is strong, versatile and appropriate for many different fibres and blends of fibres.

Textile designers plan and develop patterns, knit and weave construction, prints, textures and illustrations for fabrics and other materials that require the development of patterned surfaces. They plan the way a fabric looks and performs. They design the structure of the fabric and make decisions about appropriate yarns, colour use, surface patterning, texture and finishing (What is Textile Design, 2010). Textile designers develop fabrics used in furniture, soft furnishings, clothing, vehicles and products such as luggage. They can apply the same skills to the development of patterns for wallpapers, laminates and patterned plastics. They design fabrics to satisfy marketing and manufacturing requirements. They balance aesthetic and functional aspects; they consider the nature of yarn types, thicknesses, weights and textures to produce fabrics to cost and production constraints.

This source concludes that, textile designers advise and liaise with others who work in industries where it is necessary to predict future colour trends. They monitor trends in industries such as interior design, automotive design and fashion and progressively evolve fabric styles to meet these specific needs (Textile Design, 2009).

The review of "design" exposes and explains the conceptual application of the word in various fields of study. From (Design and Art, 2009) a created design should serve both functional and aesthetical purposes. Furthermore, the researcher agrees with Dziers (2006), who states that, Textile designing is the creation of stylish and contemporary designs. Again, it requires special skills to create innovative designs. The researchers are of the view that, the understanding derived from these authorities will assist in the creating challenging fabric designs which will serve both aesthetical and functional purposes for upholstery fabrics. Upholstery fabric is tightly woven fabric. The thread count is more and it wears better. It does not wiggle or move around. It is often heavy. It is tough, durable and do not soil or fade. It is sometimes also known as home furnishings or decorator fabric and is usually 54 inches wide. Upholstery fabric usually has a balanced weave, where all the yarns are about the same size and strength. A twill weave upholstery fabric resists wear and shows soil less than a plain weave of similar quality (Upholstery fabric, 2009). Newman (2009) also attests that, Jacquard fabrics tend to be rather expensive, but the designs created in the fabric won't fade or wear out as easily as printed designs. Because the back of some of these fabrics often expose quite a bit of the thread used in the weave, they should be backed or used in situations where the back of the fabric will not be exposed. This type of weave is very popular for upholstery fabric, and most true tapestries are made in this manner. The production of upholstery fabrics can be traced since the discovery of man when animal skins were used to upholster furniture. Upholstery fabric production used to be hand-woven but now mechanized to satisfy the demand of mass production. But in choosing upholstery, the choice of hand-woven and machine-made depends on the individual. The yarns for upholstery as explained can be natural or synthetic but it is understood that, the use of blends (which explains yarns from natural and synthetic put together) will give a durable fabric for furniture. According to the review, cotton fibre dominates the natural yarns used for upholstery. Other fibres like polyester, nylon among others are also employed for upholstery.

Again, it is emphasized that, the fabric selected for the upholstery has a great impact on the final appearance, comfort and durability of the furniture piece. Colour and design obviously play a large part in the decision making but it is equally important to consider the fibre content, weave structure and any surface treatment. Upholstery fabric weaves as deduced from the review can be flat or pile. The flat weaves are the basic weaves such as plain, twill, satin and sateen weaves whilst the pile are explained as the complex weaves like velvet, plush, corduroy among others. These weaves can be plain and decorative but their appearances depend on the order of interlacing. Jacquard patterns, when carefully analysed, may be seen to contain combinations of plain, twill, and satin weaves, even in the same crosswise yarn (Jacquard, 2011). This explains that, the use of the broadloom to weave upholstery fabric designs is practicable because, the complex weaves produced by machines are just the combinations of the basic weaves and tapestry effect. A major advantage of Jacquard machine is its ability to selectively pick individual yarns to create images in fabrics and this is a limitation with shaft looms which the broadloom is not an exception. Alternatively, the researchers are of the view that, combining the basic weaves to design upholstery fabrics is practically feasible with the broadloom.

However, the nature of the weave structure and its effects depend on the purpose of the fabric. Whether the woven fabric design is loose, tight, decorative, artistic, charming among others, the main objective of designing and producing 
upholstery fabrics is the ability to balance the aesthetic and functional aspects of the fabric. The objective of the researchers to produce hand-woven upholstery fabric designs was not after aesthetics and functions but to communicate their understanding of weaving as a practice to the general public as attested by Spirkin (2011) who states that, like philosophy, art also has a profoundly communicative function. Through it, people communicate to one another their feelings, their most intimate and infinitely varied and poignant thoughts.

An upholstery fabric has the ability to balance the aesthetic and functional aspects of the fabric. Furthermore, the researchers in their quest to produce hand-woven upholstery fabric designs were not after aesthetics and functions but to communicate their understanding of weaving as a practice to the general public as attested by Spirkin (2011) who states that, like philosophy, art also has a profoundly communicative function. Through it people communicate to one another their feelings, their most intimate and infinitely varied and poignant thoughts.

\subsection{Materials and Methods}

The materials used for producing the upholstery fabric were mainly different types of yarns. These yarns included fancy yarns with different physical appearances, counts and twists. These yarns were chosen because of their uniqueness in texture, tensile strengths among others from the normal spun yarns or the conventional spun yarns. Moreover, they also added some textural effect as far as aesthetical value was concerned. Other materials and equipment used was Broadloom and its accessories. The four-shaft broadloom was chosen for this project because the researchers sought to explore the possibilities of creating complex weave structures that may appear impossible using this type of loom. These items were used in different ways to suit the materials and techniques employed for the creation of innovative upholstery fabric designs.

As a Practice-based research, the study aims to advance knowledge partly by means of practice. This type of research is an original investigation undertaken in order to gain knowledge and understanding. It includes the invention of ideas, images, performances and artefacts including design, where these lead to new or substantially improved insights in the field of practice. Moreover, practice-based research is also a research where some of the resulting knowledge is embodied in the artefact. Whilst the significance and context of that knowledge is described in words, a full understanding of it can only be obtained with reference to the artefact itself (Candy, 2010). As a practice-based research, it was conducted in the Textile weaving studio of Kwame Nkrumah University of Science and Technology. The production processes and the invention of ideas and explorations of the woven samples were executed solely in the studio.

\subsection{Woven Samples of Akyem Designs}

The commencement of the actual weaving process, begun with a plain weave design which serves as border design was produced by stepping on two different treadles alternatively. The border design consisted of one inch each of white polyester thread sandwiched by half an inch of yellow polyester thread. The design sample combines tapestry technique and a plain weave check effect. The tapestry design was created by alternating two separate treadles to create the required sheds for picking the weave at the demarcated areas of the fabric. A plain weave which served as a binder was used successively to create an additional effect at the background of the tapestry designs. Another set of treadles were also responsible for binding the fabric. The tapestry design was traditionally known as akyem design as shown in figures:1-11

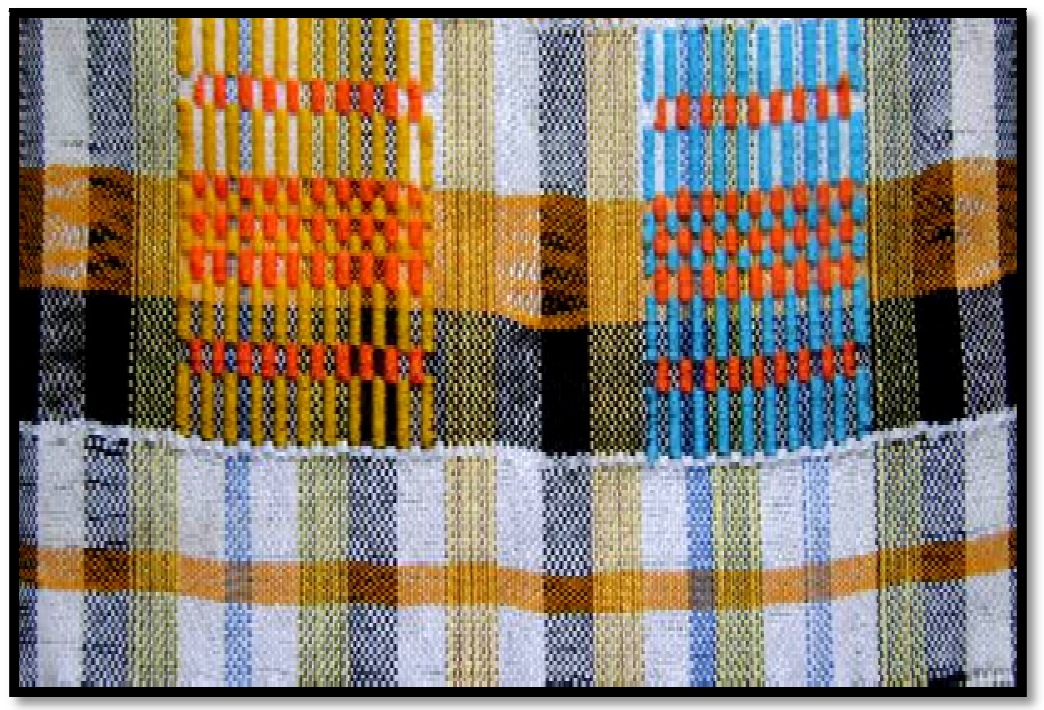

Figure 1: Akyem Design One 


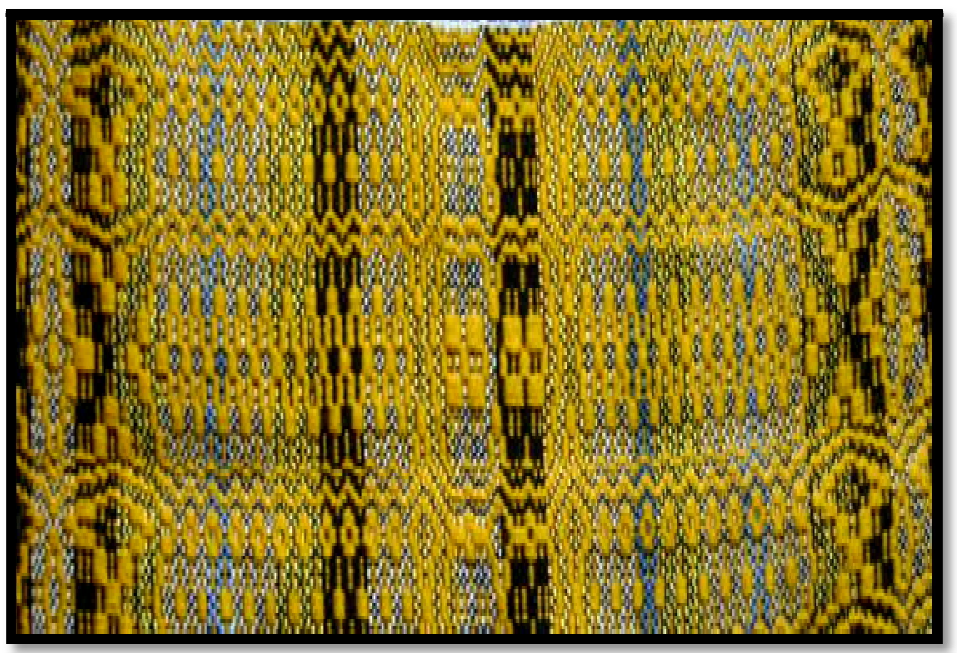

Figure 2: Akyem Design Two

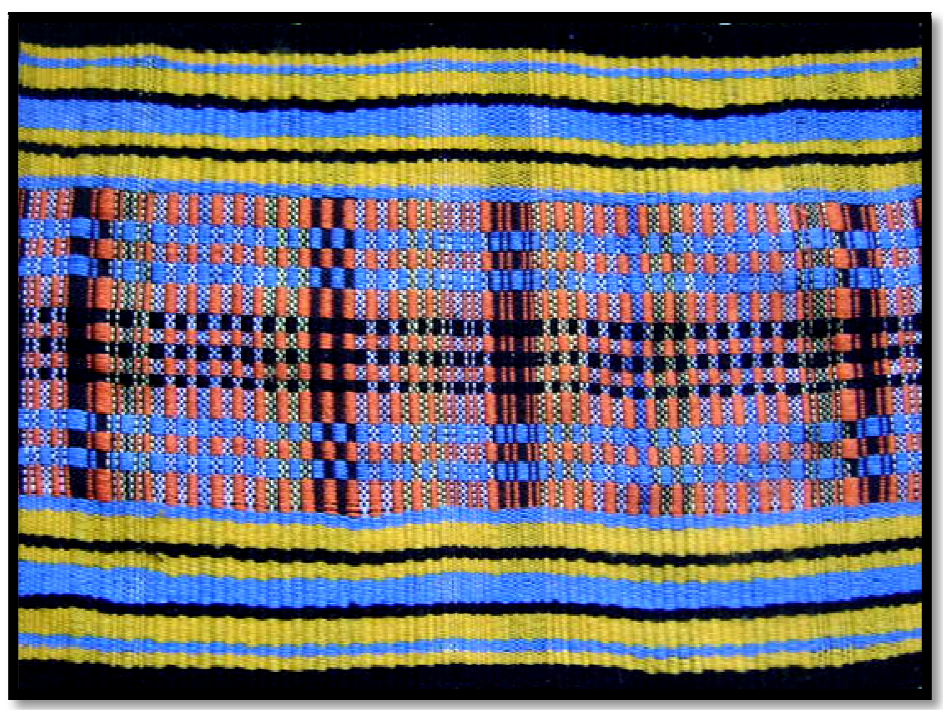

Figure 3: Akyem Design Three

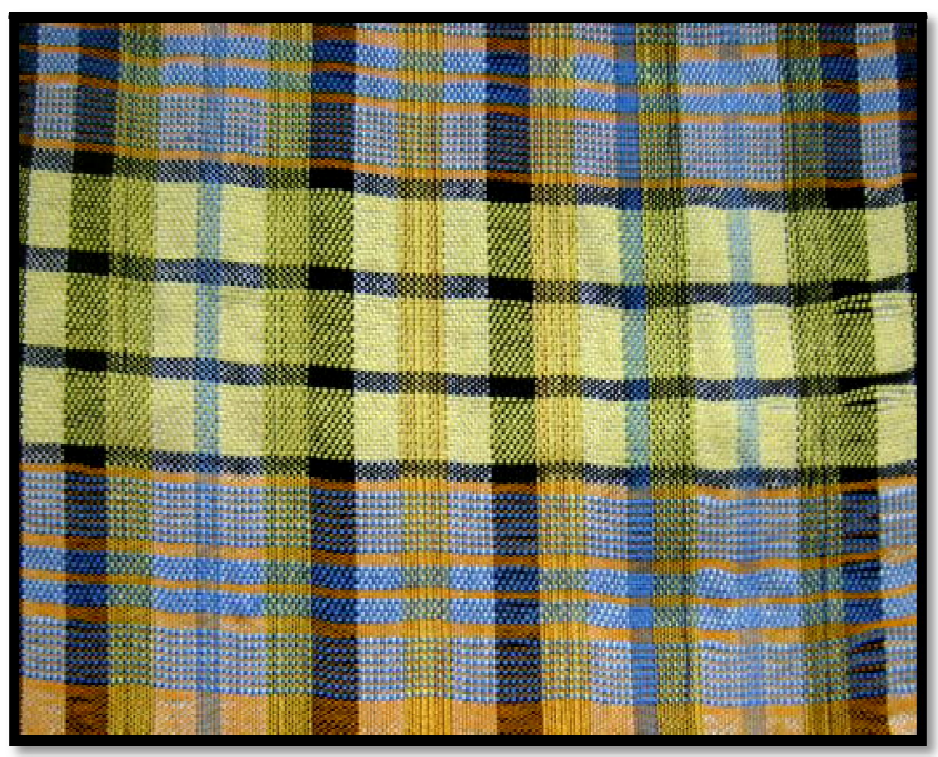

Figure 4: Akyem Design Four 


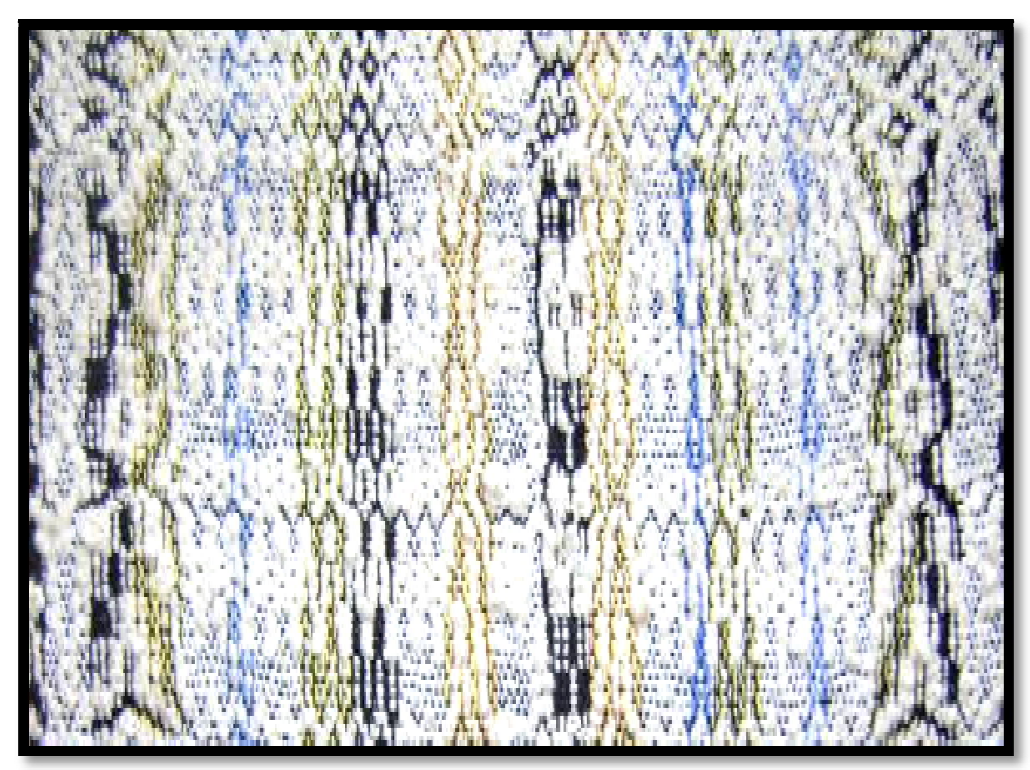

Figure 5: Akyem Design Six

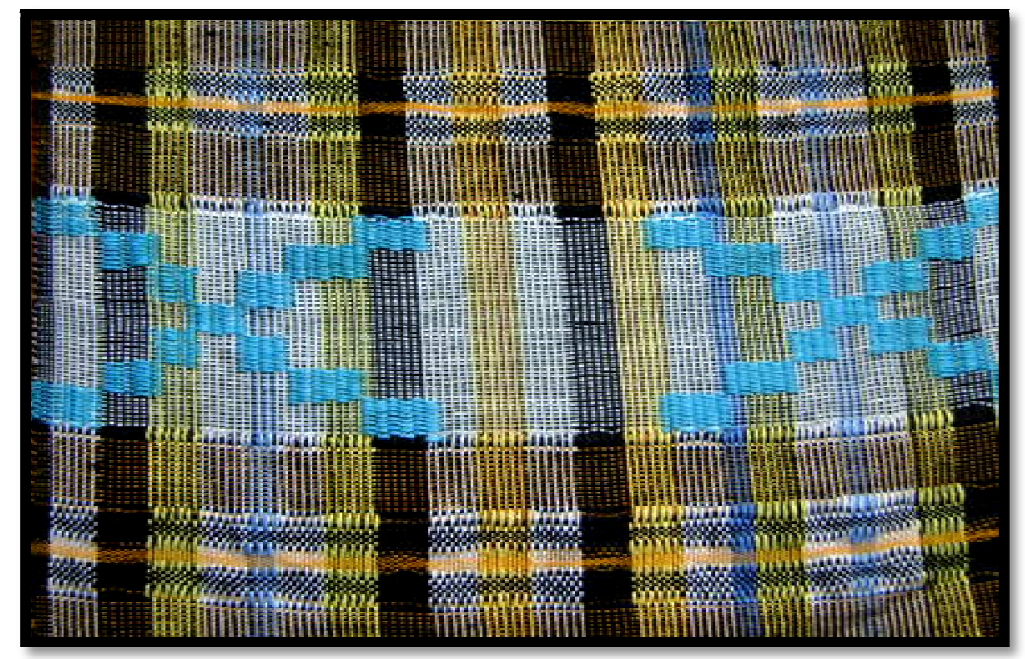

Figure 6: Akyem Design Seven

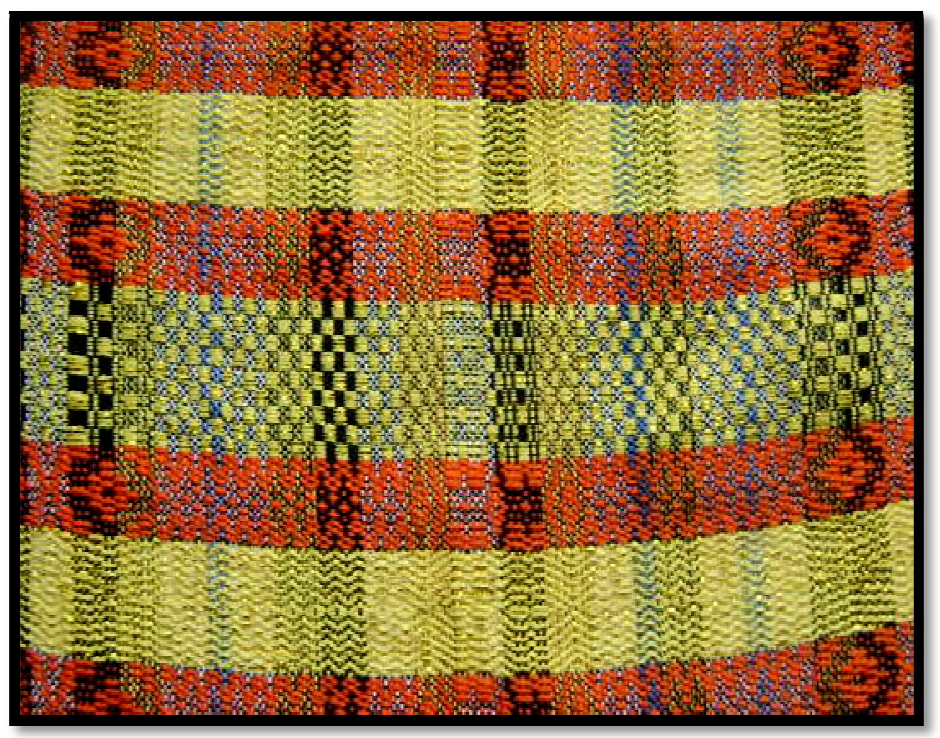

Figure 7: Akyem Design Seven 


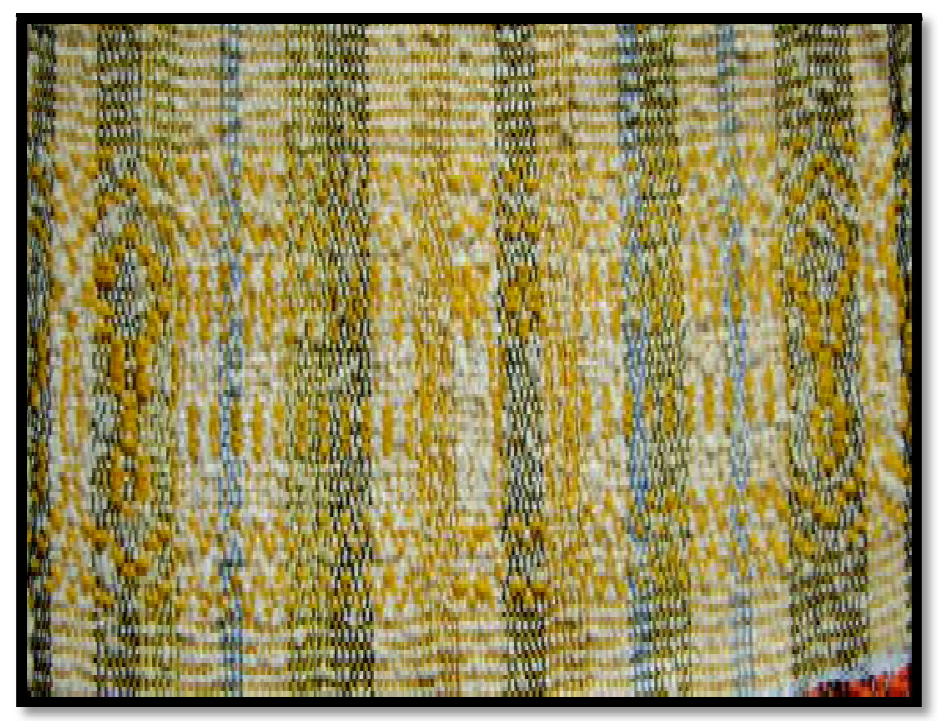

Figure 8: Akyem Design Eight

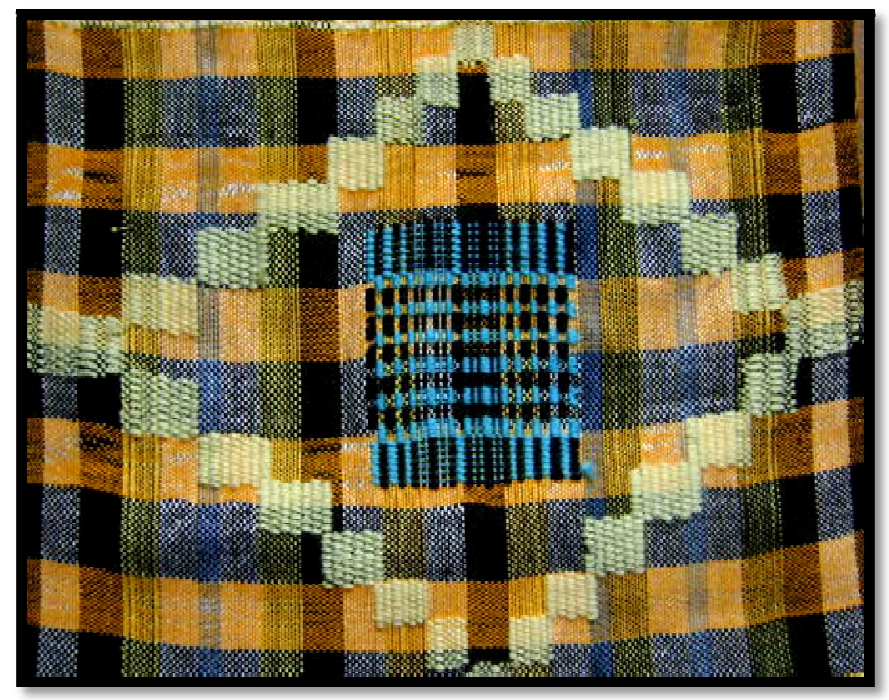

Figure 9: Akyem Design Nine

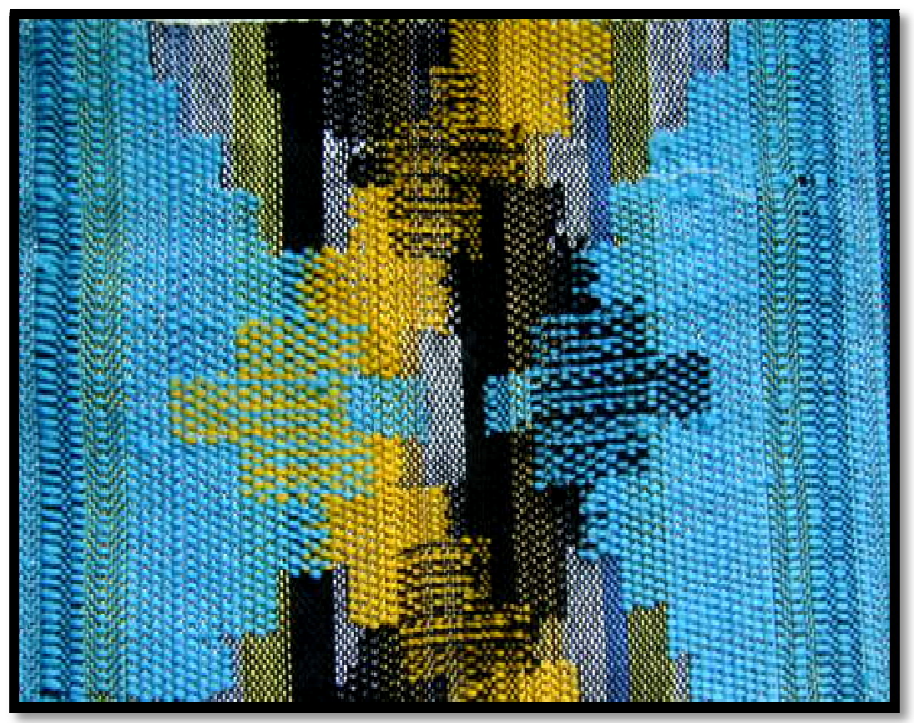

Figure 10: Akyem Design Ten 


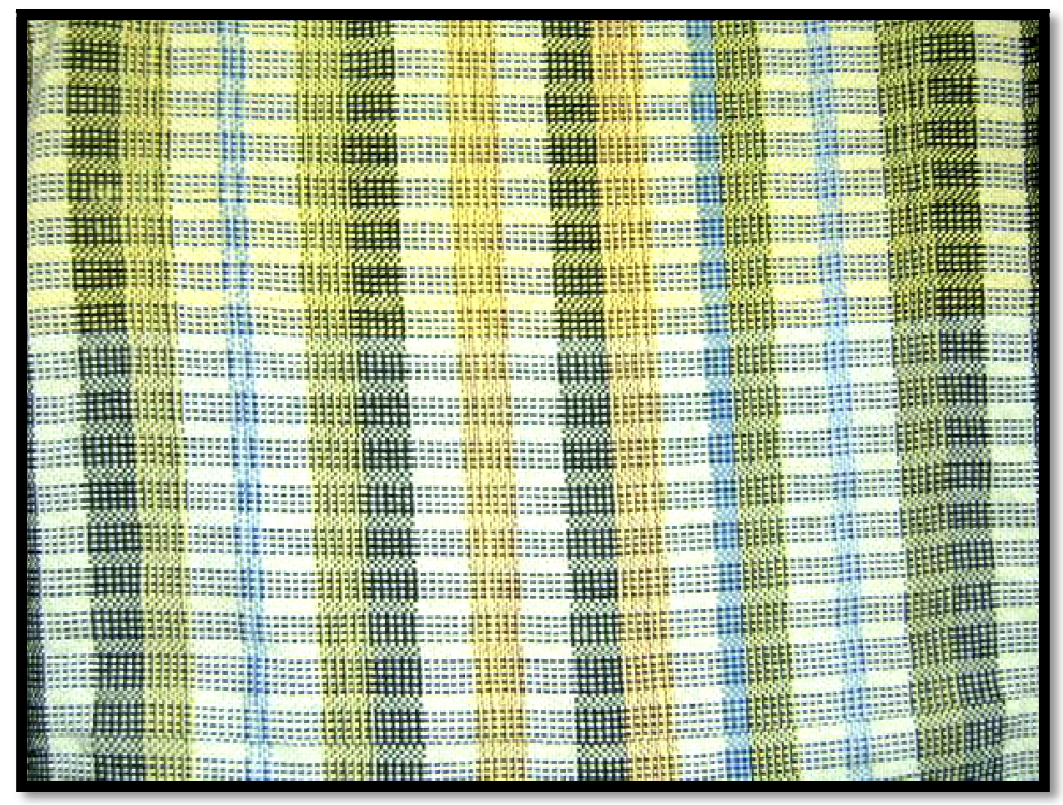

Figure 11: Akyem Design Eleven

\section{Result and Discussions}

This section deals with the presentation and discussion of the final results of the woven samples produced as well as the philosophical concept or artist statement behind the study. In addition, it outlines and discusses field research results that were obtained during the study. The discussion of the result is focused on the aesthetic qualities with reference to their respective construction techniques and their suitability as upholstery fabric designs for furniture. The methods used in creating these weaves were ascertained by heddling and stepping order. A tie-up arrangement determined are responsible for the outcome of the weave structures. In addition, the aesthetic effects produced are as a result of the different yarn types and hand picking.

\subsection{Design 1: Woven Sample}

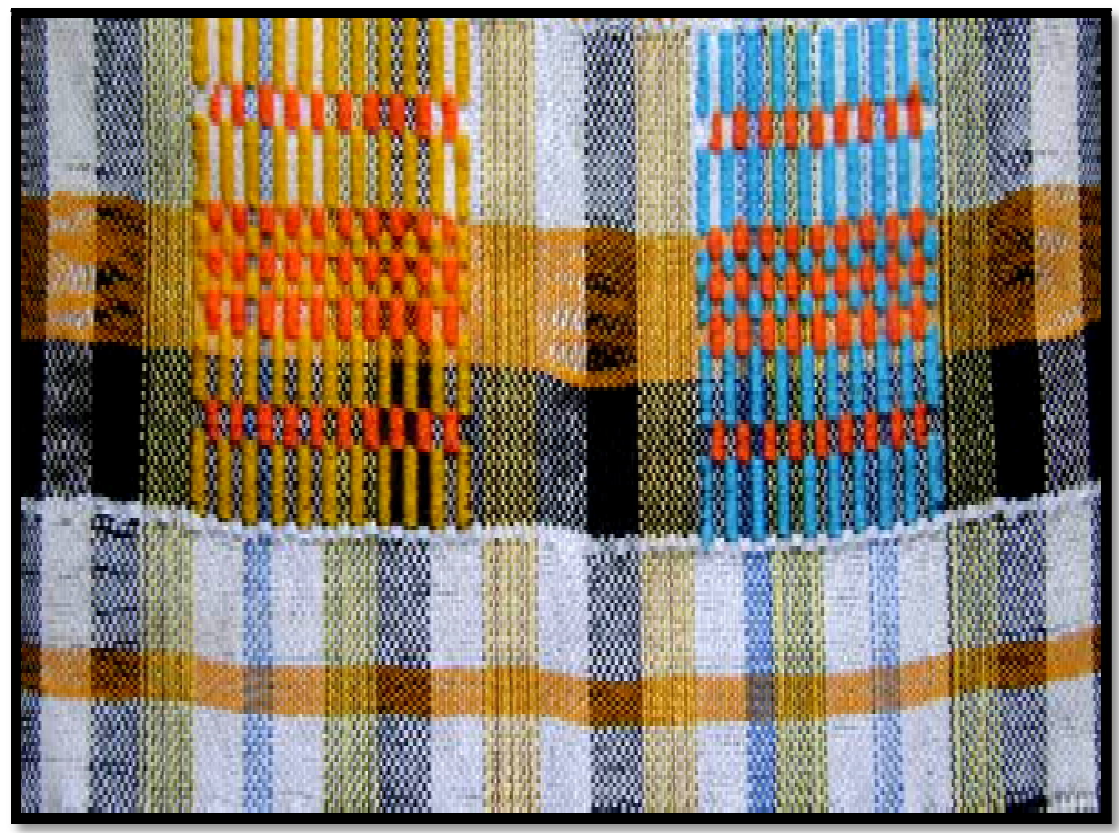

Figure 12: Woven Sample of Akyem Design

The combination of akyem design and plain weave was employed in developing this design. The aesthetical appearance of upholstery fabric is considered; however, the functional aspect of the fabric is of prior importance. Considering the basic weaves, the plain weave was considered to be the strongest and most durable. Mabey (2010) affirms that, plain weave is very strong, versatile and appropriate for many different fibres and blends of fibres. The akyem design was introduced to add beauty and a taste of tradition to the sample. The plain weave was used as a binder to make the sample 
compact to suit its functional purposes and aesthetically enhance the fabric because of the plain weave check effect in the background. This sample as an upholstery fabric will be suitable for offices and conference rooms because of less traffic on the material.

\subsection{Design 2: Woven Sample}

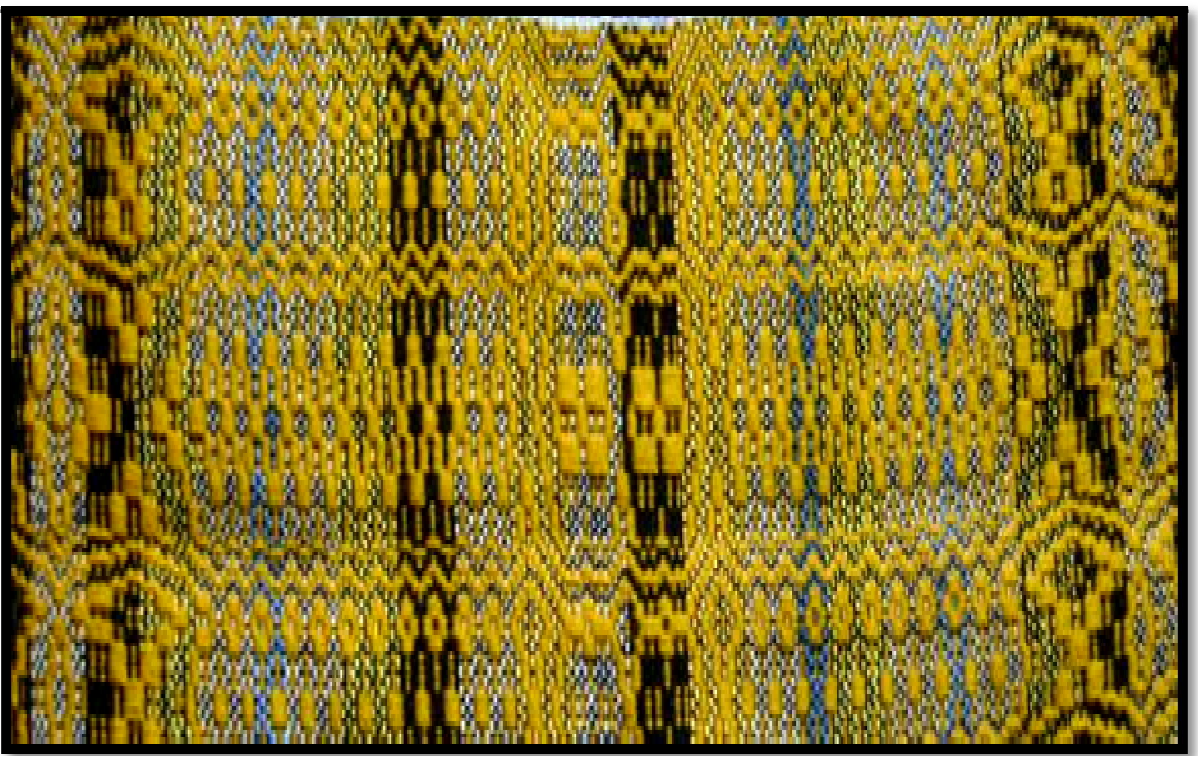

Figure 13: Woven Sample of Akyem Design

The design exhibits three different twill effects. According to Elgier (2008), twill weave is somewhat similar to plain weave. Twill weave is durable, heavier, wrinkle and soil resistant, and is more flexible than plain weave. The twill effects at the selvedges of the cloth is different from the adjacent twill effects whilst the mid- twill is also showing its own effect. Again, the background of these effects is bound with black plain weave to secure the twill weaves. The twill weave is considered as the strongest weave after the plain weave and the combination of these two weaves make this sample suitable for furniture with regular usage.

\subsection{Design 3: Woven Sample}

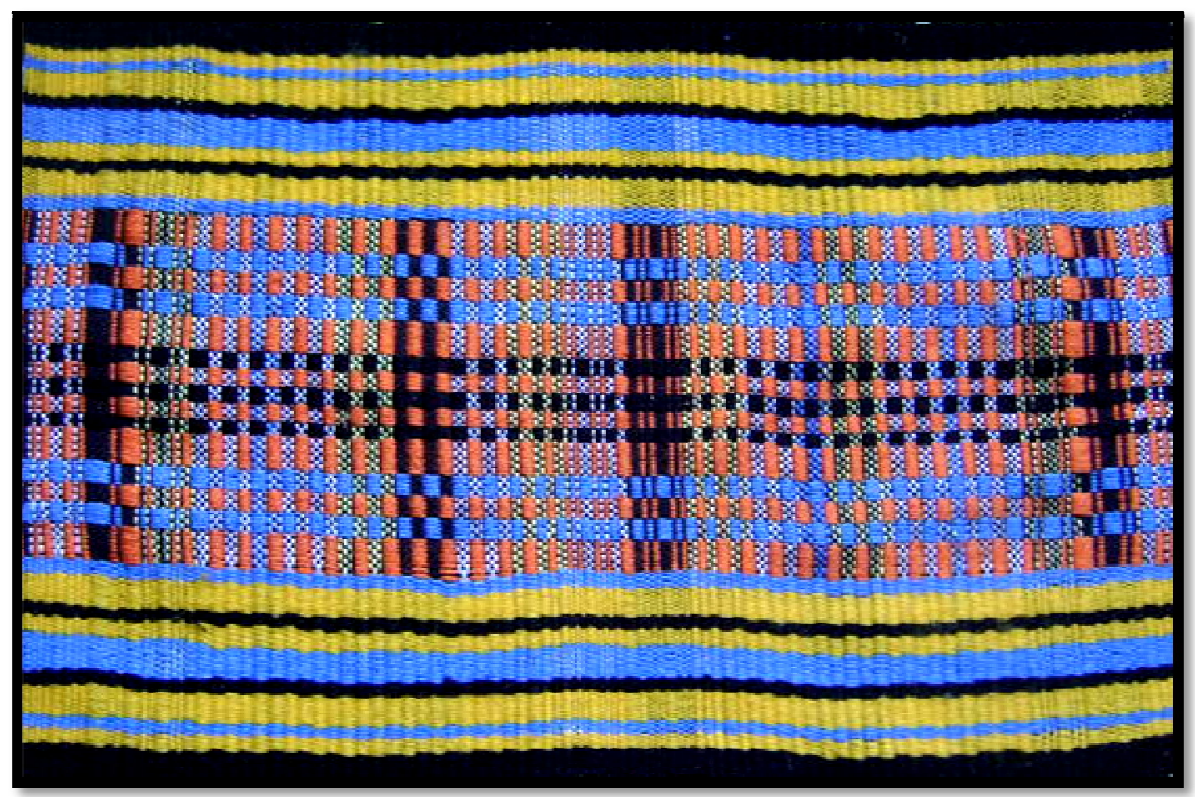

Figure 14: Woven Sample of Akyem Design

This woven sample has traditional aesthetic effect. It is attested that fabric designs play an important part in making the fabric more beautiful and more fashionable. It reflects the craftsmanship as well as the customs or culture of the wearer (Fabric Design, 2007). The novelty is using traditional concept in contemporary upholstery fabric designs. The border of the 
sample is babadua with black, yellow and turquoise blue colour effects. Turquoise blue, orange and black colours were also combined for akyem effect to give a rich Kente identity. However, the durability of the weave is secured with a plain weave serving as the binder. The structural strength identified with this sample makes it suitable for furniture used in public offices and traditional settings.

\subsection{Design 4: Woven Sample}

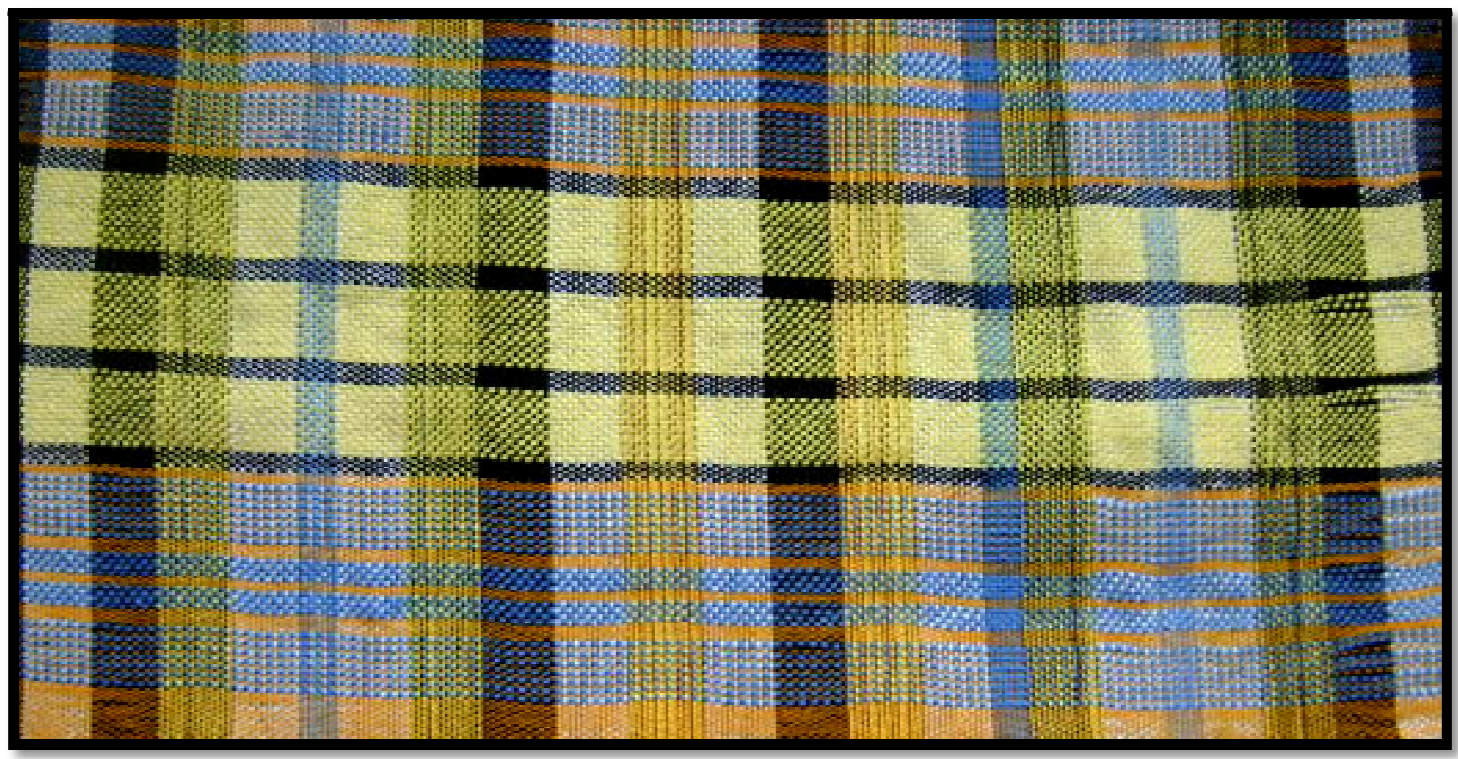

Figure 15: Woven Sample of Akyem Design

The concept of colour and weave effect was employed in producing this woven sample. The novelty in this sample is the textural effect achieved as a result of using different yarn counts in plain weave. The distribution of colour in the sample makes it physically appealing. With reference to its functional purpose, it is highly recommended for every furniture because of the structural properties such as durability and tenacity of the sample, as attested to by Dixon (2008), plain weave is the strongest of the weaves and their durability depends on the strength of the yarns and closeness of the weave. This sample as an upholstery fabric is suitable for offices and conference rooms.

\subsection{Design 5: Woven Sample}

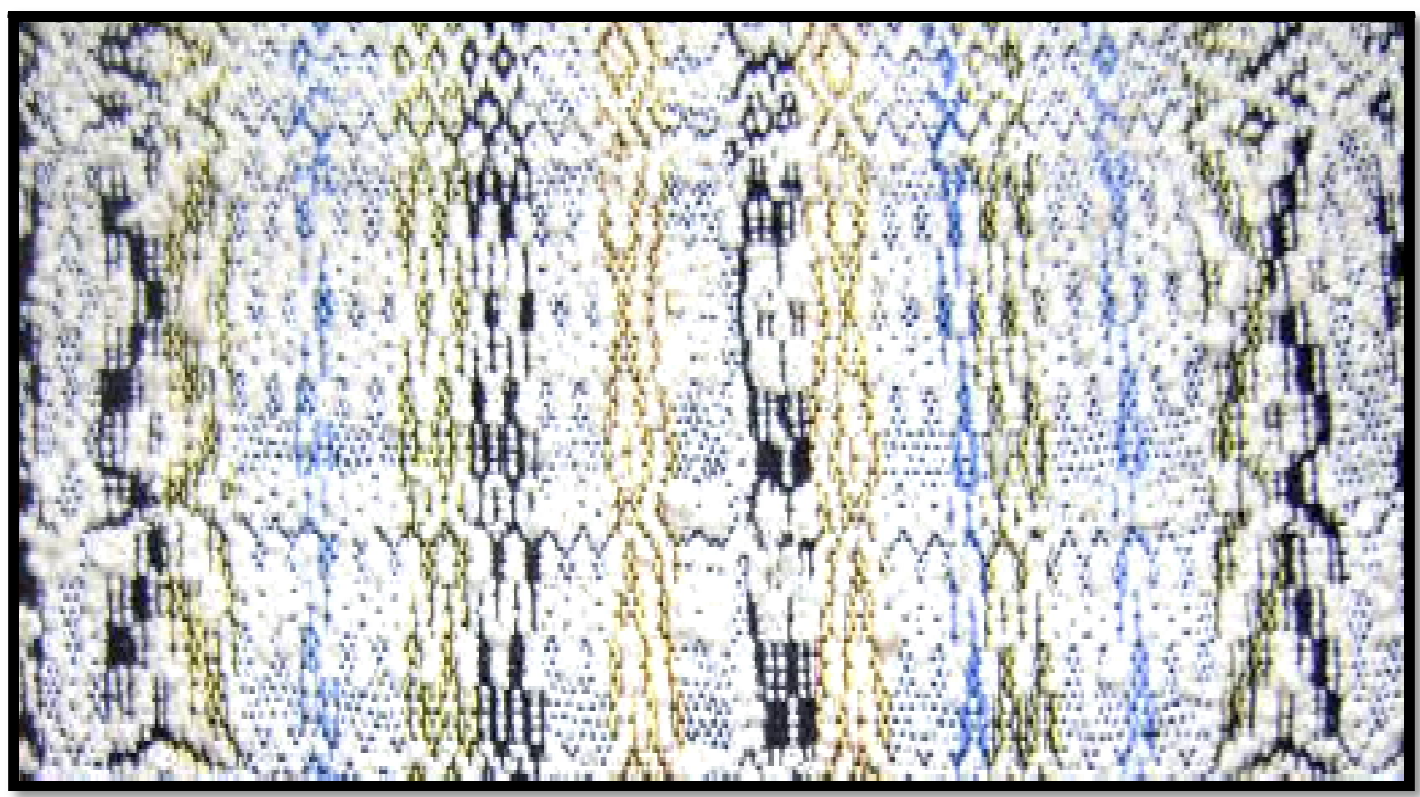

Figure 16: Woven Sample of Akyem Design 
The use of slub fancy yarn gave the sample a unique textural appeal. The weave is a derivative of woven sample two in plate 5.2, with plain weave as a binder. Its suitability as upholstery fabric is relative because in choosing upholstery fabrics, the rate and kind of exposure of the furniture needs to be considered. Tremblay and Williams (2010) explain that, some upholstery fabrics are better suited to specific areas. Furniture in high use areas (family rooms and kitchens) must be durable and easy to maintain. Elegant textiles with complex textures may be more suitable for low traffic areas such as formal living rooms. In agreement with this statement, this sample is suitable for less exposed areas like offices and formal living rooms.

\subsection{Design 6: Woven Sample}

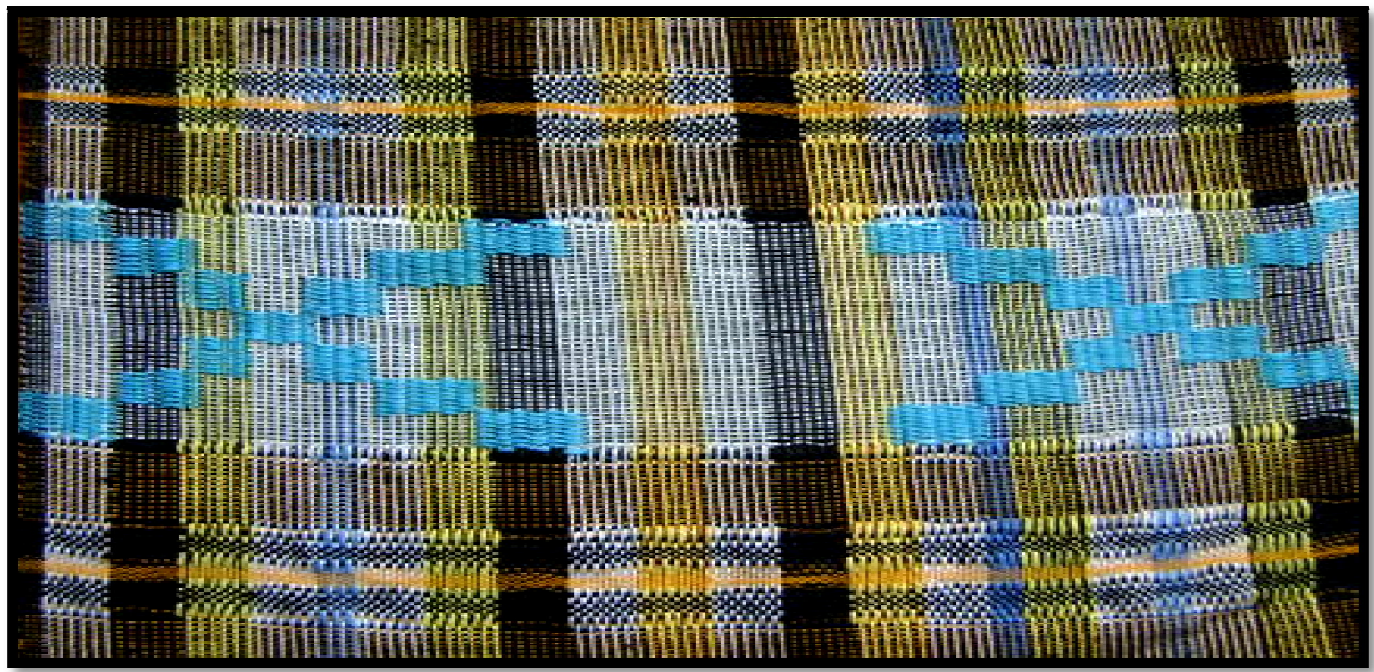

Figure 17: Woven Sample of Akyem Design

Hand-picking, shuttle throwing and weft inserts were employed in this design. The use of weft inserts and handpicking of a Kente motif called mpoakron was explored in creating this sample. In considering the functional aspect of this fabric, it is recommended that, the fabric is given a backing to strengthen it if the fabric is considered for highly exposed furniture. It was identified that, a latex finish is sometimes applied to the back of loosely woven or pile fabrics to keep the grain line from shifting or to hold the pile in place (Upholstery Basics, 2009). The beauty of this design may be of interest to consumers with unique tastes in textural appeal.

\subsection{Design 7: Woven Sample}

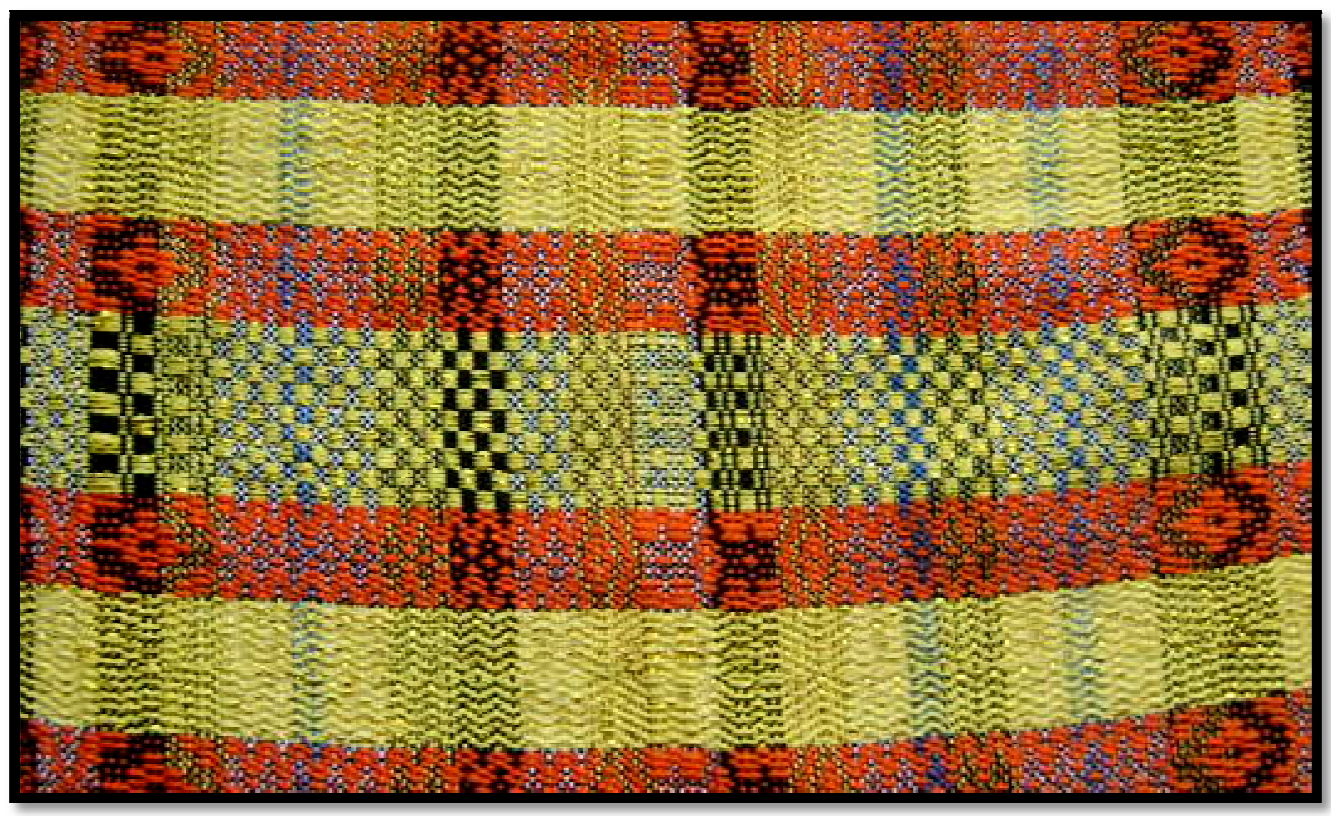

Figure 18: Woven Sample of Akyem Design 
The concept of simple and complex twill weaves used in between akyem design is employed in this sample. The complex twill is alternated with the simple twill showing orange and cream colours respectively. The akyem design is picked in cream colour together with silver metallic yarn which adds a reflective effect to the sample. This effect is obvious in the areas where cream colour is prominent in the sample. Again, plain weave was used to make the sample durable. This sample is suitable for offices and family houses.

\subsection{Design 8: Woven Sample}

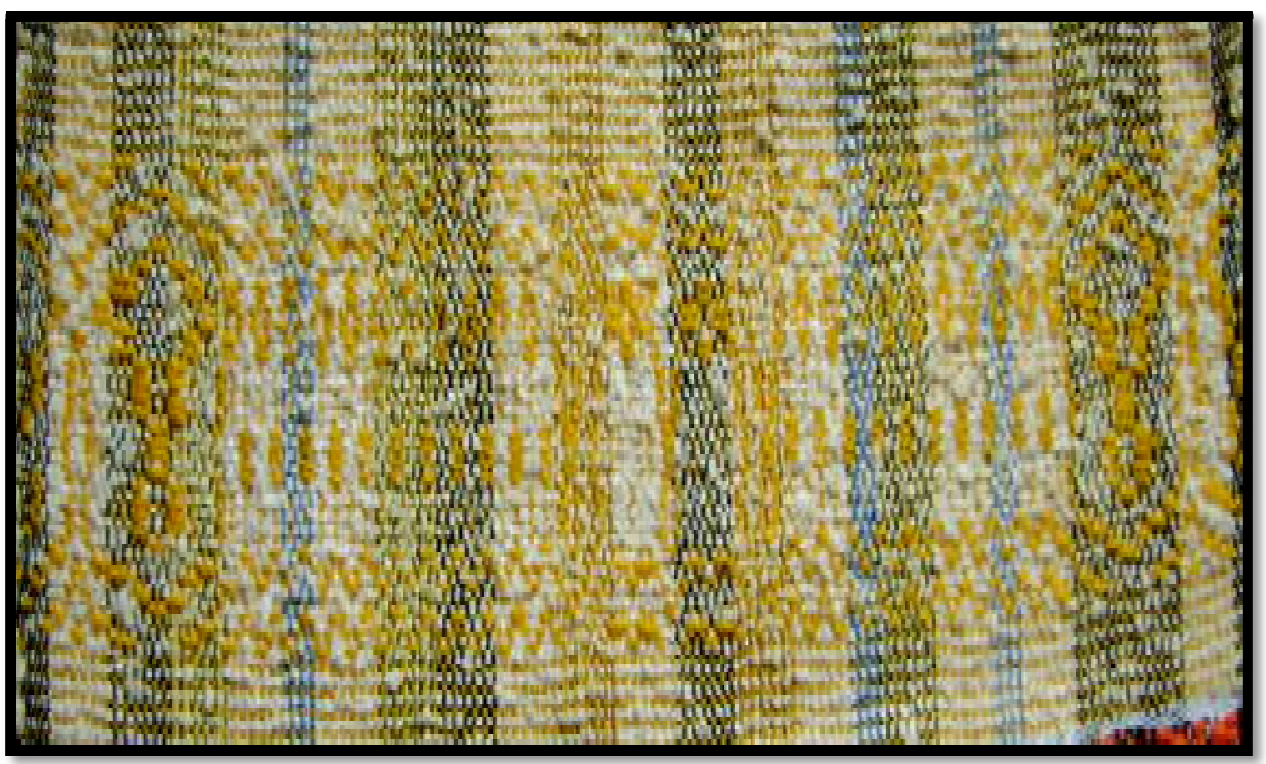

Figure 19: Woven Sample of Akyem Design

This sample was considered as a unit however, it can be separated from each other because of design individuality or as a unit. It is comprised of a woollen yellow and a white slub fancy yarn employed in a plain weave and colour effect. Interestingly, the slub fancy yarn served as a binder whilst the woollen yarn was used in picking the twill weave. It is recommended for individuals who have preference for textural fabrics and low traffic furniture.

\subsection{Design 9: Woven Sample}

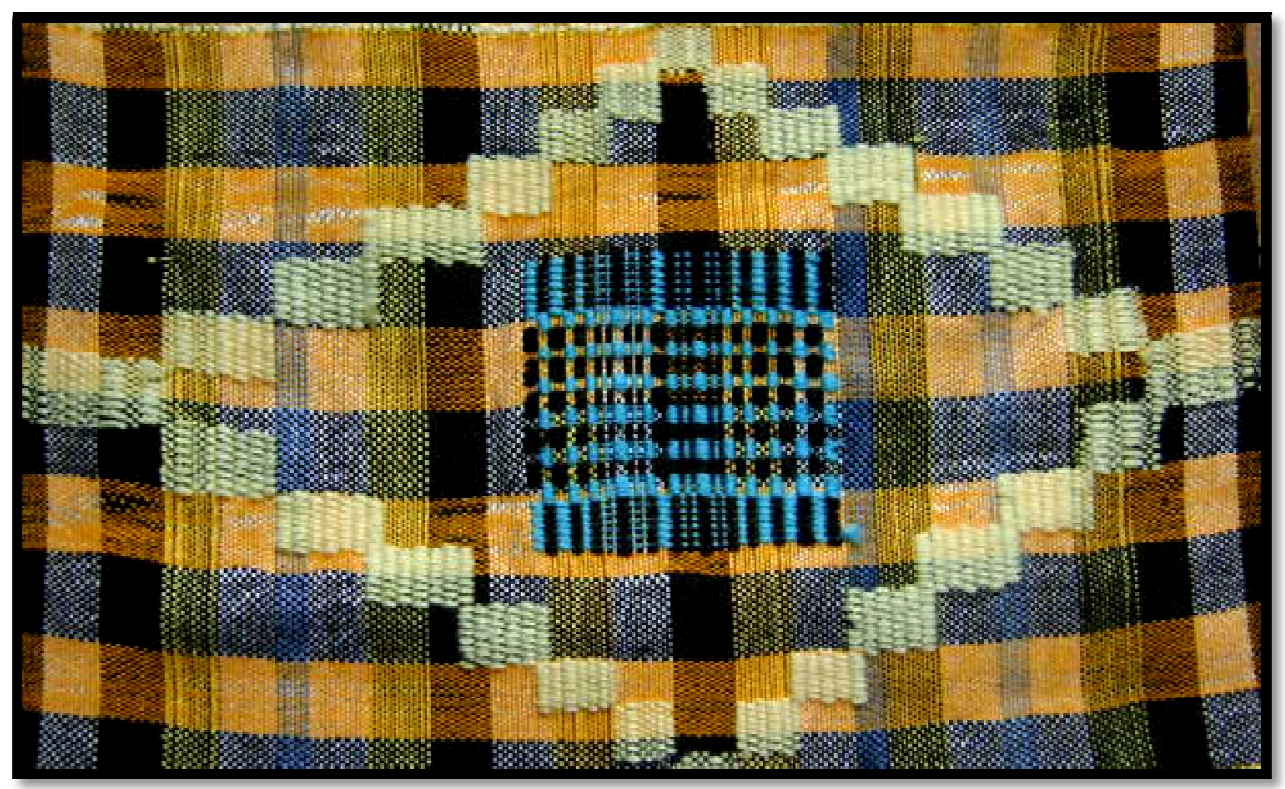

Figure 20: Woven Sample of Akyem Design 
A diamond shaped design was picked in cream colour with black and yellow plain weave check serving as the background of the design. There is black and turquoise blue akyem effect placed in the middle of the diamond design. This design will be suitable for furniture used in palaces and other traditional settings. The combination of these samples may give a unique aesthetical appearance to furniture.

\subsection{Design 10: Woven Sample}

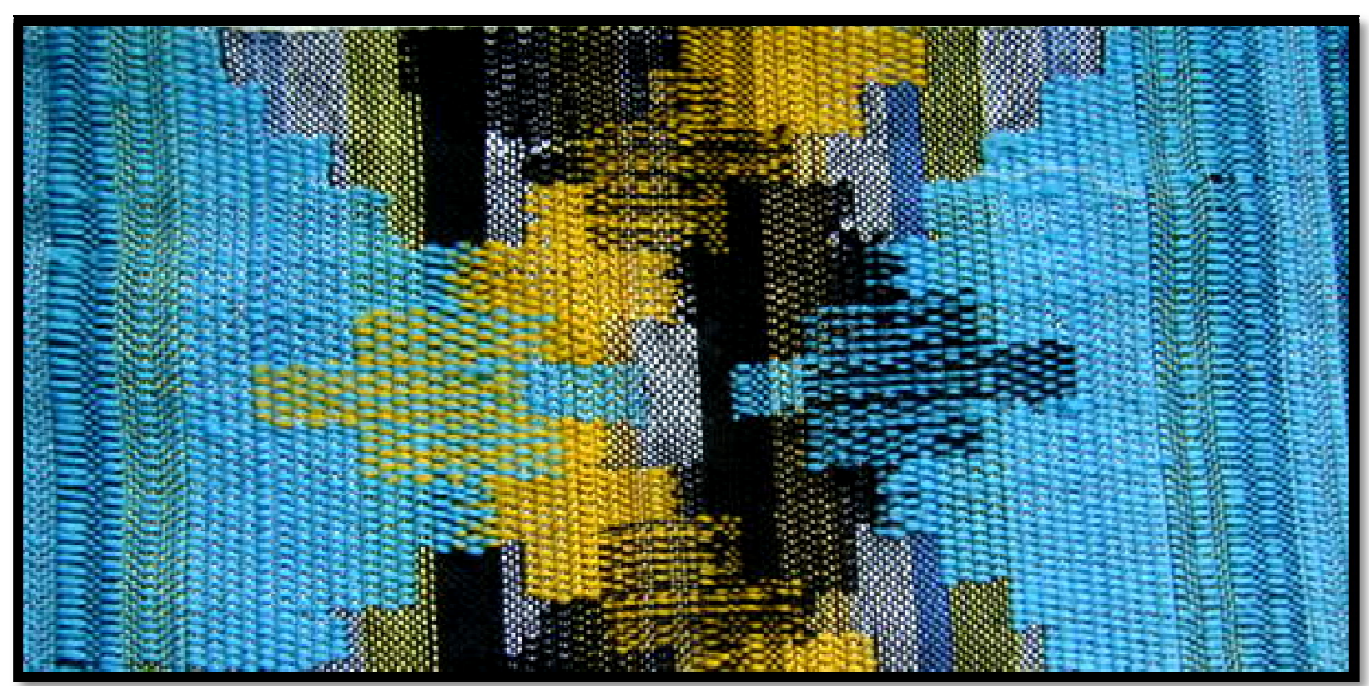

Figure 21: Woven Sample of Akyem Design

The interesting effect of one colour blending into one another is identified as the innovation in this sample. The colours of turquoise blue, yellow and black were hand-picked together to give the illusion of different diamond effects in the sample. The difficulty of introducing one colour into the other makes this sample very challenging and interesting among the samples produced. The design will not only enhance the furniture in offices and traditional settings again, will make the eye travel around the fabric.

\subsection{Design 11: Woven Sample}

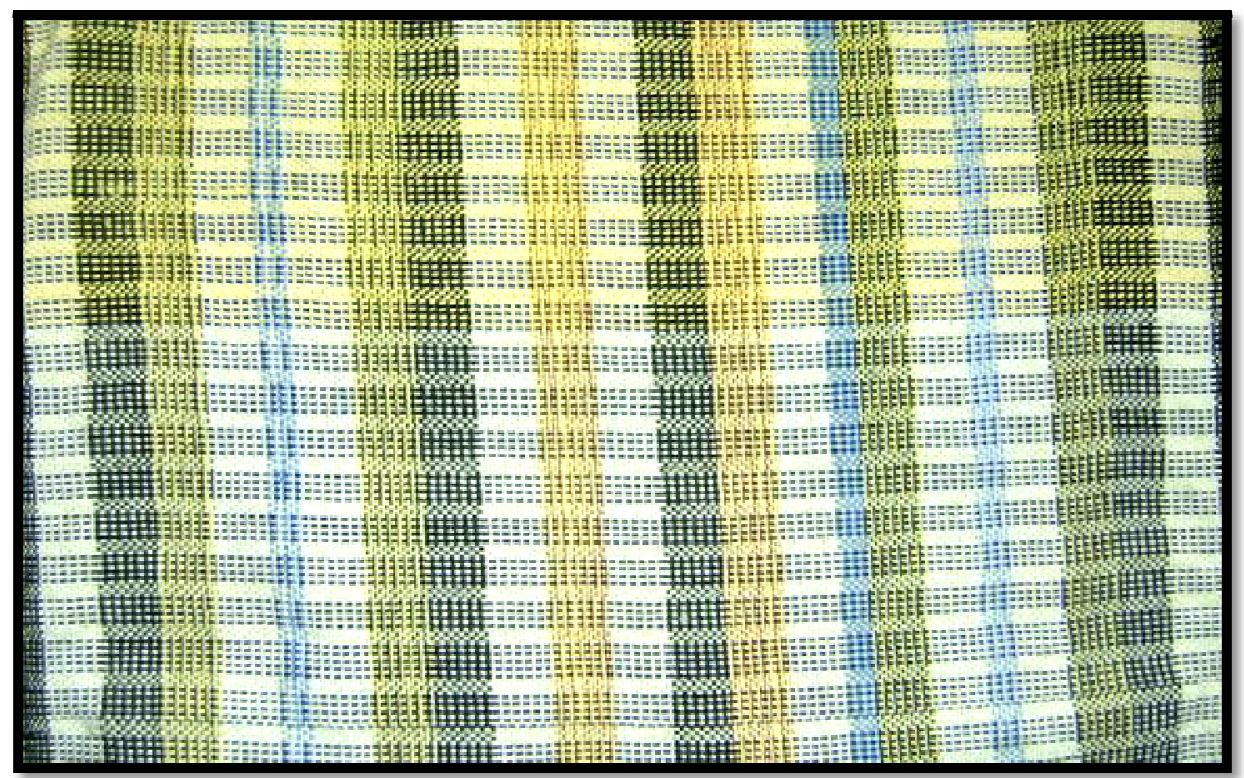

Figure 22: Woven Sample of Akyem Design

This sample is a derivative of sample four in plate 5.4. In rendering this effect, cream colour was alternated with black in plain weave. This sample however gives more of a striped effect than that of sample four which shows a checked effect because of colour alternation. It can be used as upholstery fabric for furniture in a family house.

These samples were created on a four-shaft broadloom. The weaves used for the samples have their strengths and weaknesses as fabric structures. During production, some of the weaves were used individually within a sample, whereas two 
or more weaves were combined in other samples to complement each other. This is in line with Soller (2004) who states that, each weave type has its advantages and disadvantages in tenacity depending on the order of interlacing. The idea of introducing tapestry effects was also considered. Traditional Kente motifs such as akyem, babadua, diamond and mmpuoakron were also used to enhance the samples and to add traditional taste to the fabric. The quality of a fabric depends mostly on the type of yarn and weave used in its construction. Dixon (2008) explains that, fabrics can be grouped into categories according to their weave or surface design. The durability of the weave depends on the strength of the yarns and closeness of the weave. To some extent, these factors determine the end use of the fabric produced.

The functional and aesthetic aspects of the samples were considered during production. Much can be said about the aesthetic effects of the textures and weave patterns but less can be identified about different colour ways. The functional aspect of the samples cannot be attested since there were no tests on the mechanical properties of the samples. However, these samples as upholstery fabric designs becomes fulfilling because the use of any upholstery fabric depends on the kind and rate of exposure of the furniture. In reference of Grovenor (2010), different fabrics used as upholstery give varying results; they can be soft and luxurious, or coarse and hardwearing. It all depends on the primary function of the piece of upholstery, where it will be situated and the amount and rate of exposure. There was a great challenge in acquiring yarns for the project but a few fancy yarns were gathered for the production of the samples. Novelty weaves however, are created by using a variation or a combination of the basic weaves (Upholstery Basics, 2009). Even though there were challenges in producing the samples with reference to types of yarn and colour, there is creativity and innovation in the woven samples produced.

\section{Main Findings}

In order to produce the samples, the upholstery market was observed and upholstery sellers and furniture producers were interviewed to access information on the suitability and qualities of upholstery fabric designs. The researchers employed an observational guide and interviewed upholstery merchandisers, furniture producers and fabric structure experts respectively. The field research findings are discussed in the next section of the report.

\section{Conclusions}

Everybody talks about weaving, uses the word, but only a few know what a loom is. Fewer still have experienced the rhythm, the beat, the movement of the weaver and the loom as they work in the age-old process known broadly as weaving (Karen, 2010). This first craft of man to cover his nakedness runs through every culture in all countries. Today, the main objective of using fabric has extended to various end uses including covering of furniture. The art of hand-weaving in every tradition gives a unique identity and relatively portrays the philosophical meanings of the lives and beliefs of the people. Hand-woven fabrics have their own unique aesthetical and functional values that differentiate them from machine-woven fabrics. According to Katherine (2010), hand-weaving is a relic for museums, crafts fairs, and people in search of something special. Hand-woven upholstery fabrics revealed by the study can be used for furnishing furniture. Significantly more emphasis should be placed on the type of yarn and the weave structure. These should be strong to withstand the varying pressures and abrasions that the furniture would be subjected to. Again, the colours of the fabrics play a major role in determining the buying and selling of the fabrics. Weavers should concentrate on dark colours rather than light colours because of the dusty nature of the environment. the durability of upholstery fabrics whether hand-woven or machine-woven depends on the type of yarn, weave structure and most of all, the rate and the kind of exposure that the furniture is exposed to.

\section{References}

i. Abbott, C.C. (1977). "A Study to determine.... Designers and Upholsterers", Thesis and Dissertations. Texas Tech University: Graduate Faculty.

ii. Albers, A. (1974). On Weaving: Middletown, Connecticut, USA: Wesleyan University Press.

iii. Arts and Crafts (2006). Retrieved November 17, 2010, from http:/ / www.eternalegypt.org/

iv. Art Methodology (2011). Wikipedia, the free encyclopaedia. Retrieved December 15, 2010, from http:/ / en.wikipedia.org- Art-Methodology/ wiki/

v. Atwater, M.M (1924). Hand Weaving. Harvard Square - Cambridge, Massachusetts. USA: The Shuttle-Craft Co. Inc,

vi. Blanchard, S. (2007). What are the Best Fabrics for Upholstery? Retrieved November 11, 2010, from http:/ / www.essortment.com/ articles/

vii. Candy, L. (2010). Practice-Based Research. Retrieved October 18, 2010, from http:/ / www.creativityandcognition.com/ content/ view/ 124/ 131/

viii. Castillo, J.J. (2009). Research Population. Retrieved November 10, 2010, from http:// www.experimentresources.com/ research-population.html

ix. Chandler, D. (2011). Jacquard Weaves. Retrieved 8 November, 2010, from http:/ / www.bookdepository.co.uk

x. Colgrove, D. (2010). Fabric Characteristics - Types of Fabric. Retrieved November 4, 2010, from http:/ / furniture.about.com/

xi. Davies, P. (2001). Exploratory Research. Retrieved October 10, 2010, from http://www.examiner.com/scholarlyresearch-in-san-jose/ exploratory-research

xii. Definition of Qualitative Research (2011). Retrieved November 21, 2011, from http://www.mrcbsu.cam.ac.uk/cochrane/ handbook500/ chapter_20/20_2_1_definition_of qualitative_research.html. 
xiii. Descriptive Research Paper (2011). Retrieved October 15, 2011, from http:/ / www.pureresearchpapers.com/ types/ descriptive-research-paper.asp

xiv. Design and Art (2009). Wikipedia, the free encyclopaedia. Retrieved December 15, 2010, from http:/ / en.wikipedia.org/ wiki/

xv. Dixon, A. (2008). The Handweavers Pattern Directory: Over 600 Weaves for Four-shaft loom (Handback). Interweave press. Pg. 21

xvi. DJS Research Ltd (2010). What is Exploratory Research? Retrieved August 6, 2011, from http:/ / www.marketresearchworld.net/ index.php?

xvii. Dziers, M (March 20, 2006). Textile Design. Retrieved March 3, 2011, from http://www.indiacrafts.com/ textiledesign.html

xviii. Elgier, T (2008). Types of Fabric Weaves. Retrieved November 18, 2010, from http:/ / www.teonline.com/articles/

xix. Estimating Fabric Yardage (2011). Retrieved March 12, 2011 from http:/ / www.reviews.ebay.com/

xx. Gates, D. (2008). Upholstery Fabrics. Australia: Murdock Books Printing Ltd. Pg. 24

xxi. Gray, C. and Malins J. (1993). The Centre for Research in Art and Design. Gray's School of Art, Faculty of Design. Scotland, UK: The Robert Gordon University, Aberdeen.

xxii. Grevenor, A. (2010). Selecting the Most Suitable Fabric for Your Upholstery. Retrieved November 11, 2010, from http:/ / www.articlesnatch.com/

xxiii. Hand-weaving: Meaning and Definitions. Retrieved August 4, 2011, from http:/ / www. dictionary infoplease.com

xxiv. Hann, M.A and Thomas, B.G (2005). Patterns of Culture: Decorating Weaving Techniques. No. 36 in the Ars Textrina Series, published in association with University of Leeds International Textiles Archives (ULITA)

xxv. Hopkins, M. (2008). Upholstery. Holland: New Holland Publishers Ltd. Pg. 35

xxvi. Ivanova, I. (2010). Interior-Designer-Owner, Bogari. Retrieved October 27, 2010, from http:/ / www.bogarifurniture.com/

xxvii. Katherine, J. (2010). Why hand-weaving is a technology for the 21st century. Retrieved September 23, 2011, from http:/ / www.theecologist.org/

xxviii. Kelley, N. (2009). Fabric Properties and Distinctions: Selecting Upholstery Fabrics. Textile Fabric Consultants, Inc. Retrieved December 20, 2010, from http:/ / www.fabrics.net/ amyupholstery.asp/

xxix. Kicklighter, C.E (2001). Upholstery Fundamental. Goodheart-Wilcox Publishers, pg. 20

xxx. Knupfer, N.E and McLellan, H. ( 2001). Descriptive Research Methodologies. Retrieved October 8, 2011, from the Associations for Educational Communications and Technology (AECT), 1800 North Stonelake Drive, Suite 2 Bloomington, IN 47404, http:/ / www.aect.org/ edtech/ ed1/ 41/ 41-01.html

xxxi. Larson, B. (2010). How to Choose an Upholstery Fabric. Retrieved November 14, 2010, from http:/ / www.1stupholsteryfabric.blogspot.com/

xxxii. Leedy, P.D and Ormrod, J.E (2002). Practical Research: Planning and Design. (Eighth Edition). New Jersey: Pearson Prentice Hall.

xxxiii. Luther, S. (2010). All about Fabric Weaves. Retrieved October 16, 2010, from http:/ / www.xzcution.com/

xxxiv. Mabey, B. (2010). Interior Decorating Sofa Fabrics and How to Choose the Best. Retrieved November 20, 2010, from http:/ / ezinearticles.com/?

xxxv. Madigan, K. (2010). Soari: Self Discovery through Free Weaving. Retrieved November 16, 2011, from http:/ / www.saoriglobal.com/ tabid/ 71/ Default.aspx

xxxvi. Mare, E.C (24/ 06/ 09). So what is Design? Retrieved November 18, 2009, from http:/ / www.designcouncil.com/

xxxvii. Maxin, E. (2010). Introduction to Upholstery Fabric. Retrieved December 17, 2010, from http:/ / www.homeinstitute.com/

xxxviii. Methodology (2008). Retrieved November 10, 2011, from http:// www.ukdissertation.com/ methodology.php

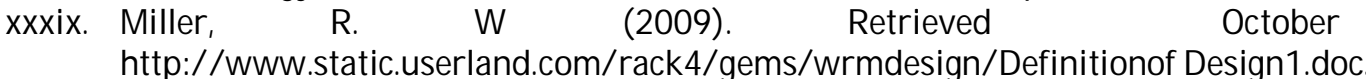

xl. New Collections (2007).Trevira - The Fibre Company No.8. Retrieved November 21, 2010, from http:/ / www.treviracs.com/

xli. Newman, A. (2009). All about Fabric Weaves: A Tutorial. Retrieved October 19, 2010, from http:/ / sew4home.com/ tips-resources/ buying-guides/

xlii. Parma, S. (2010). Different Types of Weaves. Retrieved September 6, 2010, from http:/ / www.fibre2fashion.com/ Industry-article/ 11095/ different-types-of-weaves4.asp

xliii. Qualitative Research (2011). Wikipedia, the free encyclopaedia. Retrieved December 15, 2010, from http:/ / en.wikipedia.org/ wiki/

xliv. Research Design (2011). Wikipedia, the free encyclopaedia. Retrieved December 15, 2010, from http:/ / en.wikipedia.org/ wiki/

xlv. Rolling, J.H. (2010). National Art Education Association Studies in Art Education: A Journal of Issues and Research 2010, 51(2), 102 - 114. Retrieved November 21, 2011, from http:/ / www.bcartsweek.org/ assets/ uploads

xlvi. Schneider, J. (1987). The Anthropology of Cloth. New York: Graduate Centre, City University of New York, NY 10036 
xlvii. Selecting Furniture Fabric, Understanding Furniture Fabric (2008). Retrieved November 16, 2010, from http:/ / www.neirc.org/ .

xlviii. Selecting Fabric for Upholstery (15/12/09). Retrieved October 20, 2010, from http:/ / kravet.typepad.com/inspiredtalk/

xlix. Seymour, R. (2002). What is Design, Design Council's: Design in Business Week. Retrieved 13 November, 2010.

l. Siber, M. (2004). Writing an Artist's Statement. Chicago: Columbia College. Revised November, 2011.

li. Soller, J. (2004). Weave Definitions. Retrieved October 11, 2010, from http:/ / www.solarcomposites.com/

lii. Spirkin, A. (2011). Philosophy and Art. Retrieved September 20, 2011 from http:/ / www.marxists.org./ reference/ archive/ spirkin/ works/ dialectical-materialism/ ch01-s05.html

liii. Stone, J. (2003). Consumer Choices: Understanding apparel and Furnishing Textiles. Edited by Laura Sternweis, Extension Communication Specialist. Reviewed by Sara Kadolp, Assistant Professor, Textiles and Clothing.

liv. Textile Design (2010). Retrieved October 8, 2010, from http:/ / www.india-crafts.com/ textile/ textile-design.html

lv. Tortora Phyllis, G and Merkel Robert, S. (2005). Fairchild's Dictionary of Textiles - 7th Edition. New York: Fairchild Publications. Pp. 625

lvi. Tremblay, K.R and Williams, K (12/ 05/ 07). Selecting Upholstered Furniture for Your Home. Retrieved October 23, 2010, from http:/ / www.ext.colostate.edu/ pubs/ consumer/

lvii. Upholstery Basics (2009). Cowles Creative Publishing. Retrieved November 19, 2010, from http:/ / books.google.com.gh/ books?

lviii. Upholstery Colour, Pattern and Texture (2008). Retrieved October 18, 2010, from http:/ / books.google.com.gh/ books?

lix. "Upholstery", Encarta World English Dictionary (1999). London: Bloomsbury Publishing Plc.

lx. Upholstery Fabric (2009). Textile Pattern/ Indian Motif (8/10/09). Retrieved December 11, 2010, from http:/ / www.4to40.com/

lxi. Upholstery (2010). Wikipedia, the free encyclopaedia. Retrieved December 15, 2010, from http:/ / en.wikipedia.org/ wiki/.

lxii. Ward, M. (2010). Design Review. Retrieved October 10,2010 from http:/ / www blog.echoenduring.com

lxiii. Webster, M. (1985). Webster's ninth new collegiate dictionary. Meriam - Webster Inc. Retrieved November 10, 2011 from http:/ / www.socialresearchmethods.net/ tutorial/ Mugo/ tutorial.html.

lxiv. What are the Different Weaving Techniques (2010). Retrieved October 14, 2010, from http:/ / www.wisegeeks.com/

lxv. What is Innovation. Retrieved October 13, 2010, from http:/ / www.realinnovation.com

lxvi. What is Textile Design (2010). Retrieved October 10, 2010, from http:/ / www.graphicdesignbasics.com/

lxvii. What is Weaving (2010). Retrieved November 24, 2010, from http:/ / www.wisegeeks.com/ what-is-weaving.html

lxviii. Wiley, J. (2008). Apparel Research. Retrieved November 16, 2010 from http:/ / www.apparelsearch.com

lxix. Writing a Literature Review (2009). Retrieved 29 November, 2010, from http:/ / www.smu.ca/ administration/ library/ litrev.html

lxx. Wynne, A. (1997). Textiles. Macmillan Education Ltd, London and Basingstoke. Pp. 166-167 in hand-woven fabrics which can influence the aesthetic and visual appeal of furniture.

lxxi. In view of this, the project seeks to design and produce weave structures using the broadloom with the aim of discovering innovative upholstery fabric designs and to encourage the use of locally made upholstery fabrics. 